\title{
Using Combined TEM, Raman, XRD, and VNIR techniques to Investigate Secondary Phase Formation and Textural Relationships in Brine + Jarosite Experiments
}

\author{
K. Miller ${ }^{1}$, C. Phillips-Lander ${ }^{1}$, G. Strout ${ }^{2}$, J. Bishop ${ }^{3}$, A. Elwood Madden ${ }^{1}$ and M. Elwood Madden ${ }^{1}$ \\ 1. School of Geology and Geophysics, University of Oklahoma, 100 E. Boyd St., Rm 710 Norman, OK, \\ USA. \\ 2. SRN Microscopy Laboratory, University of Oklahoma, 770 Van Vleet Oval, Norman, OK, USA. \\ 3. SETI Institute, 189 Bernardo Ave, Suite 200 Mountain View, CA, USA.
}

We performed experimental work to determine why anhydrite $\left(\mathrm{CaSO}_{4}\right)$ forms in flow-through reactors (analogous to flowing groundwater systems), whereas gypsum $\left(\mathrm{CaSO}_{4} \cdot 2 \mathrm{H}_{2} \mathrm{O}\right)$ forms in batch reactors (analogous to closed evaporative basins) [1]. Our work is particularly relevant to sedimentary rocks on Mars where different sulfates, including jarosite $\left(\mathrm{KFe}_{3}(\mathrm{OH})_{6}\left(\mathrm{SO}_{4}\right)_{2}\right)$ and Ca-sulfates with varying hydration states, are observed in outcrops at Gale Crater [2-3]. Through experimental work and analysis of experimental samples using X-ray diffraction (XRD), Raman Spectroscopy, visible/near infrared spectroscopy (VNIR), and transmission electron microscopy (TEM), we seek to better understand how Ca-sulfate crystals nucleate [4] and grow at low temperatures. This information will inform interpretations of formation conditions of Ca-sulfates on both Mars and Earth.

Dixon et al. [1] hypothesized that anhydrite may form at low temperatures in flow-through experiments due to the constant source of high salinity, low-water activity brine, while gypsum initially nucleates in the batch reactors, increasing the activity of water as calcium and sulfate ions are consumed. Other workers have suggested that Ca-sulfate minerals form via complex nucleation, aggregation, and growth processes [4] that may also be affected by hydrologic flow rates, as well as different mineral substrates present in the system. We conducted short-term (22 day), low temperature $\left(20^{\circ} \mathrm{C}\right)$ flow-through and batch reactor experiments with different brine concentrations and mineral substrates $-\mathrm{CaCl}_{2}$ brines + jarosite and $\mathrm{MgSO}_{4} / \mathrm{MgCl}_{2}$ brines + calcite $\left(\mathrm{CaCO}_{3}\right)$ - to test Dixon et al.'s hypothesis in addition to the hypothesis that varying the mineral substrate would affect reaction products. We employed XRD to identify the reaction products formed in both flow-through and batch reactor experiments. Due to the relative insensitivity of XRD to poorly crystalline or nanocrystalline phases within the jarosite matrix, we used Raman spectroscopy $(785 \mathrm{~nm})$ as an additional analytical technique to identify and map mineral phases present in the samples. We also conducted visible/near-infrared spectroscopy (VNIR: 0.35-2.5 $\mu \mathrm{m})$ to test the possibility of detecting and resolving Ca-sulfate phases in these samples. Finally, we examined the textural relationships in the reaction products using TEM to evaluate possible nucleation pathways leading to anhydrite precipitation in flowing brines.

We identified mineral phases present in experimental samples using XRD and Raman spectroscopy. In the jarosite $+\mathrm{CaCl}_{2}$ brine experiments, akaganeite $(\mathrm{FeO}(\mathrm{OH}, \mathrm{Cl}))$ is observed as a reaction product across batch and flow-through experiments (Fig. 1c). Antarcticite $\left(\mathrm{CaCl}_{2} \bullet 6 \mathrm{H}_{2} \mathrm{O}\right)$ is also observed in most experiments, but is present in reaction product specimens due to precipitation of residual brine in the samples and was likely not present in the dissolution reactors. Gypsum is present across all experiments. Bassanite $\left(\mathrm{CaSO}_{4} \cdot 0.5 \mathrm{H}_{2} \mathrm{O}\right)$ may be present in trace amounts $(<1 \mathrm{wt}$. \%) in two flow-through experiments, but is not observed in any of the batch experiments. We observed anhydrite in flow- 
through experiments but not in batch experiments. VNIR spectra of both flow and batch samples are dominated by jarosite bands with some gypsum features. The strongest gypsum signatures are observed for the samples in the longer experiments. Anhydrite does not have features in this spectral region, as those characteristic individual bands are located between 4.2-4.5 $\mu$ [5]. We used TEM to investigate phase relationships by imaging the samples and analyzing diffraction patterns. Gypsum is the only Casulfate phase identified in batch reactor experiments, forming as relatively large $(>1 \mu \mathrm{m})$ lath-shaped crystals (Fig. 1a). Though gypsum and anhydrite are both present in flow-through experiments, the large lath-shaped particles were not observed in any of the flow-through experiments. Instead, Ca-sulfate phases seem to be associated with akageneite, both of which grow as nanoscale crystals around the edges of microscale jarosite grains (Fig. 1b). Analyses are ongoing for the calcite experiments, which were designed to test the effect of varying the mineral substrate on reaction products. Preliminary XRD data suggest that no Ca-sulfate phases formed in either flow-through or batch experiments.

Though anhydrite was identified as a reaction product across all brine concentrations in flow-through jarosite dissolution experiments, no anhydrite was observed in any of the batch reactor experiments, suggesting hydrodynamic effects are key for anhydrite formation and growth at low temperatures in the presence of jarosite. Distinctive Ca-sulfate morphologies observed in TEM between the large, lathshaped gypsum crystals in batch experiments and the interpreted nanoscale Ca-sulfates associated with jarosite grains suggest both hydrodynamic conditions and mineral substrates which may affect Casulfate phase nucleation. Although anhydrite has traditionally been interpreted as having formed at higher temperatures $>50^{\circ} \mathrm{C}$ in high salinity waters, our work, alongside that of Dixon et al. (2015) demonstrates that anhydrite may also form at lower temperatures at a range of water activities if there is significant groundwater flow. Our findings may aid in interpreting the timing and evolution of depositional environments and diagenetic conditions for the sedimentary rocks at Gale Crater and other locations where Ca-sulfate minerals have been observed $[3,6]$.

\section{References:}

[1] E Dixon et al, JGR: Planets 120 (2015), p. 625-642.

[2] M Nachon et al, JGR: Planets 119 (2014), p. 1991-2016.

[3] D. Vaniman et al, Science 343 (2014), i. 6169.

[4] T. Stawski et al, Nature: Communications 7 (2016), n. 11177.

[5] J. Bishop et al, American Mineralogist 99 (2014), p. 2105-2115

[6] J. Grotzinger et al, Science 350 (2015), i. 6257.

Funding for this project was provided by the NASA grant NNX13AG75G and the School of Geology and Geophysics at OU. Travel to the M\&M conference was covered by Timpano Award funds.

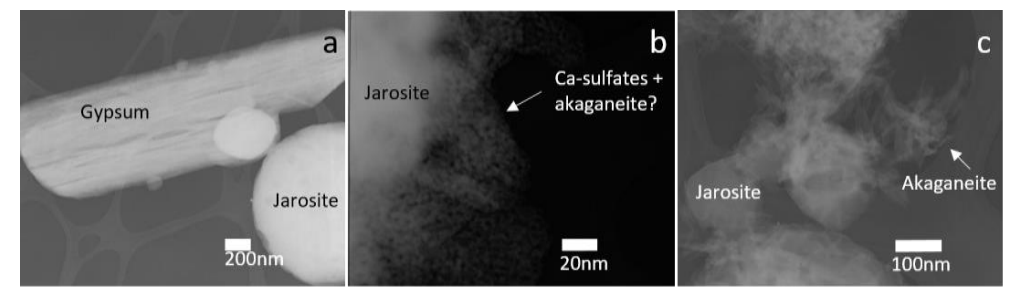

Figure 1. TEM images: a) Gypsum lathe observed in jarosite $+\mathrm{CaCl}_{2}$ batch reactor experiment b) Edge of jarosite grain in flow-through dissolution experiment covered with secondary phases - possibly Casulfates and akageneite c) Akaganeite observed covering jarosite in flow-through dissolution experiment. 